\title{
MicroRNA-433 inhibits migration and invasion of ovarian cancer cells via targeting Notch1
}

\author{
T. LIANG ${ }^{1}$, Q. GUO ${ }^{2}$, L. LI ${ }^{1}$, Y. CHENG ${ }^{1}$, C. REN ${ }^{1}$, G. ZHANG ${ }^{2, *}$ \\ ${ }^{1}$ Harbin Medical University, Bao Jian Road 157\#, Nan Gang District, Harbin City, Hei Longjiang Province, China 150001; ${ }^{2}$ Department of \\ gynecology and obstetrics, The First Affiliated Hospital of Harbin Medical University, You Zheng Street 23\#, Nan Gang District, Harbin City, \\ Hei Longjiang Province, China 150001
}

*Corresponding author: zhanggwgw@hotmail.com

Received March 10, 2016 / Accepted April 28, 2016

\begin{abstract}
We aimed to determine the effects of miR-433 on the malignant behaviors of ovarian cancer cells, as well as to elucidate the possible mechanisms of ovarian cancer development. A total of 9 ovarian cancer tissues and 9 matched normal ovary tissues were obtained, and the expression levels of miR-433 and Notch1 were then determined by real-time PCR. Human ovarian cancer cell lines SKOV3 and OVCAR3 were transfected with miR-433 mimics, negative miR-control and Notch1 siRNA. The expression of Notch1 protein in transfected cells was determined by western blot. In addition, the proliferation, migration and invasion of SKOV3 and OVCAR3 cells in vitro were then evaluated using Cell Counting Kit 8, wound healing assay and Transwell invasion assay, respectively. Besides, bioinformatics methods and luciferace reporter assay were performed to confirm whether Notch1 was a direct target of miR-433. The expression of miR-433 was markedly downregulated while Notch1 expression was significantly up-regulated in ovarian cancer tissues compared with matched normal ovary tissues. Overexpression of miR-433 significantly inhibited the migration and invasion of ovarian cancer cells, but had not significant effects on cell proliferation. In addition, Notch 1 was a direct target of miR-433. Besides, down-regulation of Notch1 inhibited the invasion of ovarian cancer cells. Our findings indicate that miR-433 may inhibit cell migration and invasion in the development of ovarian cancer via down-regulation of Notch1. Notch1 may serve as a potential target in cancer therapy.
\end{abstract}

Key words: ovarian cancer, miR-433, Notch1, migration, invasion

Ovarian cancer is the most common lethal of gynecological malignancies worldwide [1]. In 2015, approximately 21,290 new cases and 14,180 deaths in United States result from ovarian cancer according to the national cancer statistics [2]. Due to lack of symptoms at early stage, most of patients with ovarian cancer (approximately 70\%) are diagnosed at an advanced stage. Despite improvement in treatment, the overall 5-year survival rate is still about 30\% [3]. Ovarian cancer continues to be a challenging issue of women health. Although progresses have been achieved, more efforts are still needed to elucidate the molecular mechanisms underlying ovarian cancer.

Abbreviations: CCK-8 - Cell Counting Kit 8; EMT - epithelial-mesenchymal transition; FBS - fetal bovine serum; HDAC6 - Histone Deacetylase 6; FIGO - International Federation of Gynecology and Obstetrics; miRNAs

- MicroRNAs; SD -standard deviation
In several previous studies, the molecular mechanisms underlying ovarian cancer have been widely investigated. For instance, endogenous or exogenous aryl hydrocarbon receptor (AhR) ligands have been shown to inhibit cell proliferation in ovarian cancer $[4,5]$. DiGeorge Critical Region 8 (DGCR8) is reported to be associated with the malignant behaviors of human ovarian cancer cells [6]. In addition, it has been known that Notch signaling affects the development and function of several organs via regulating cell proliferation and apoptosis [7]. Especially, the key roles of Notch1 in cancer development and therapy have aroused more attentions in recent. It has been reported that the NOTCH1 signaling pathway may be a key mechanism to regulate the SHARP1mediated suppression of the epithelial-mesenchymal transition in metastasis of endometrial cancer [8]. Activated Notch1 is also shown to inhibit p53-induced apoptosis and induce cell cycle in cervical 
cancer cells [9]. Besides, Notch 1 signaling is also observed to be active in ovarian cancer [10].

Furthermore, microRNAs (miRNAs), a group of small endogenous non-coding RNAs, can target the $3^{\prime}$ untranslated region (3' UTR) of mRNAs and consequently play regulatory roles at the post-transcriptional level [11]. Increasing evidence has indicated that miRNAs can be implicated in numerous cellular processes, like cellproliferation and apoptosis $[11,12]$. MiRNAs are likely to function as tumor suppressors or oncogenes in cancer progression [13], including ovarian cancer. For example, members of the miR-200 family are observed to be down-regulated in ovarian cancer $[14,15]$, miR-199a can inhibit the tumorigenicity of ovarian cancer-initiating cells [16], and down-regulation of let-7 family is associated with chemotherapy resistant in ovarian cancer cells [15]. Recently, accumulating evidences have confirmed that miR-433 has diverse functions in tumor biology. For instance, miR-433 can inhibit cell growth and metastasis in oral squamous cell carcinoma by targeting Histone Deacetylase 6 (HDAC6) [17]. Also, miR-433 can inhibit migration of liver cancer cells by repressing cAMP response element-binding protein [18]. Besides, miR-433 is reported to negatively regulate chemotherapy sensitivity of cervical cancer cells [19]. Overexpression of miR433 in ovarian cancer cells is reported to promote resistance to paclitaxel [20], and decreased MAD2 expression by miR-433 is also shown to reduce progression-free survival in patients with epithelial ovarian cancer [21]. However, the potential role and regulatory mechanism of miR-433 in the development of ovarian cancer have not been fully investigated.

In this study, we investigated whether miR-433 was aberrantly expressed in ovarian cancer tissues. The effects of miR-433 on the proliferation, migration and invasion of ovarian cancer cells were then explored. Importantly, we further validated whether Notch1 was a target gene of miR-433. Besides, we observed the effects of Notch 1 on the proliferation, migration and invasion of ovarian cancer cells, thus to explore whether miR-433 induced malignant phenotypes of ovarian cancer through targeting Notch1. Notch1 has been shown to be a key player in a variety of cancers $[22,23]$. Our study aimed to determine the effects of miR-433 on the malignant behaviors of ovarian cancer cells, as well as to elucidate the possible mechanisms of ovarian cancer development. Our findings will help to devise possible approaches for the treatment of ovarian cancer in a clinical application.

\section{Materials and methods}

Samples collection. Our study was reviewed and approved by the Medical Ethics Committee of the First Affiliated Hospital of Harbin Medical University, and each patient was informed consent.

A total of 9 ovarian cancer tissues and 9 matched normal ovary tissues were obtained from 9 patients who underwent surgical resections for ovarian cancer at the First Affiliated Hospital of Harbin Medical University. All samples were im- mediately frozen in liquid nitrogen and then stored at $-80^{\circ} \mathrm{C}$ for subsequent experiments. Patients were diagnosed with ovarian cancer according to histopathological evaluation and all cancers were staged following the criteria of International Federation of Gynecology and Obstetrics (FIGO). All patients did not receive chemotherapy before operation. The information and the cancer stage of each patient were shown in Table 1.

Cell culture and transfection. Human ovarian cancer cell lines SKOV3 (high-invasive) and OVCAR3 (low-invasive) were purchased from the American Type Culture Collection (Rockville, MD) and were then grown in RPMI 1640 medium (Invitrogen, Carlsbad, CA) supplemented with 10\% fetal bovine serum (FBS) in a humidified incubator with 5\% $\mathrm{CO}_{2}$ at $37^{\circ} \mathrm{C}$. Cells $\left(5 \times 10^{5}\right)$ were seeded in 6-well plates and cultured in serum-free RPMI-1640 medium for 1 day before transfection. The miR-433 mimics, negative miR-control and Notch1 siRNA were synthesized by GenePharma (Shanghai, China) and then transfected into SKOV3 and OVCAR3 cells with lipofectamine 2000 reagent (Invitrogen, Carlsbad, CA) as manufacturer's instruction. SKOV3 and OVCAR3 Cells without any treatment were considered as blank control. The Notch1 siRNA sequences were as follows: sense, 5'-GUCCAGGAAACAACUGCAATT-3' and antisense, 5' UUGCAGUUGUUUCCUGGACTT-3'. After transfection, the expression of miR-433 and Notch 1 mRNA was determined by real-time PCR, and Notch 1 protein were detected by western blot assay.

RNA extraction and real-time PCR. Total RNA was extracted from ovarian cancer cell lines and ovarian cancer tissues using TRizol reagent (Invitrogen, CA, USA) according to manufacturer's protocol. cDNA was then synthesized using a miScript II reverse transcription kit (Qiagen, USA). Afterwards, quantitative real-time PCR was performed using a SYBR Green PCR kit (Applied Biosystem, USA). The PCR conditions were as follows: $95^{\circ} \mathrm{C} 10 \mathrm{~min} ; 40$ cycles of $95^{\circ} \mathrm{C}$ $15 \mathrm{sec}, 69^{\circ} \mathrm{C} 30 \mathrm{sec}$ and $72^{\circ} \mathrm{C} 30 \mathrm{sec} ; 72^{\circ} \mathrm{C} 5 \mathrm{~min}$. The relative expression of MiR-433 and Notch1 mRNA were calculated using the $2^{-\Delta \Delta C \mathrm{CT}}$ method as previously described [24]. Endogenous U6 and GAPDH mRNA was used as internal standards to normalize the expression of MiR-433 and Notch1 mRNA,

Table 1. Clinicopathological information of 9 ovarian cancer samples

\begin{tabular}{cccll}
\hline No. & Age & FIGO stage & Histotype & Grade \\
\hline 1 & 47 & II & Endometrioid carcinoma & moderate \\
2 & 49 & I & Serous cystadenocarcinoma & well \\
3 & 52 & I & Endometrioid carcinoma & moderate \\
4 & 55 & III & Serous cystadenocarcinoma & moderate \\
5 & 57 & II & Mucinous cystadenocarcinoma & moderate \\
6 & 58 & II & Serous cystadenocarcinoma & moderate \\
7 & 59 & IV & Endometrioid carcinoma & poor \\
8 & 61 & II & Serous cystadenocarcinoma & well \\
9 & 62 & I & Serous cystadenocarcinoma & moderate \\
\hline
\end{tabular}



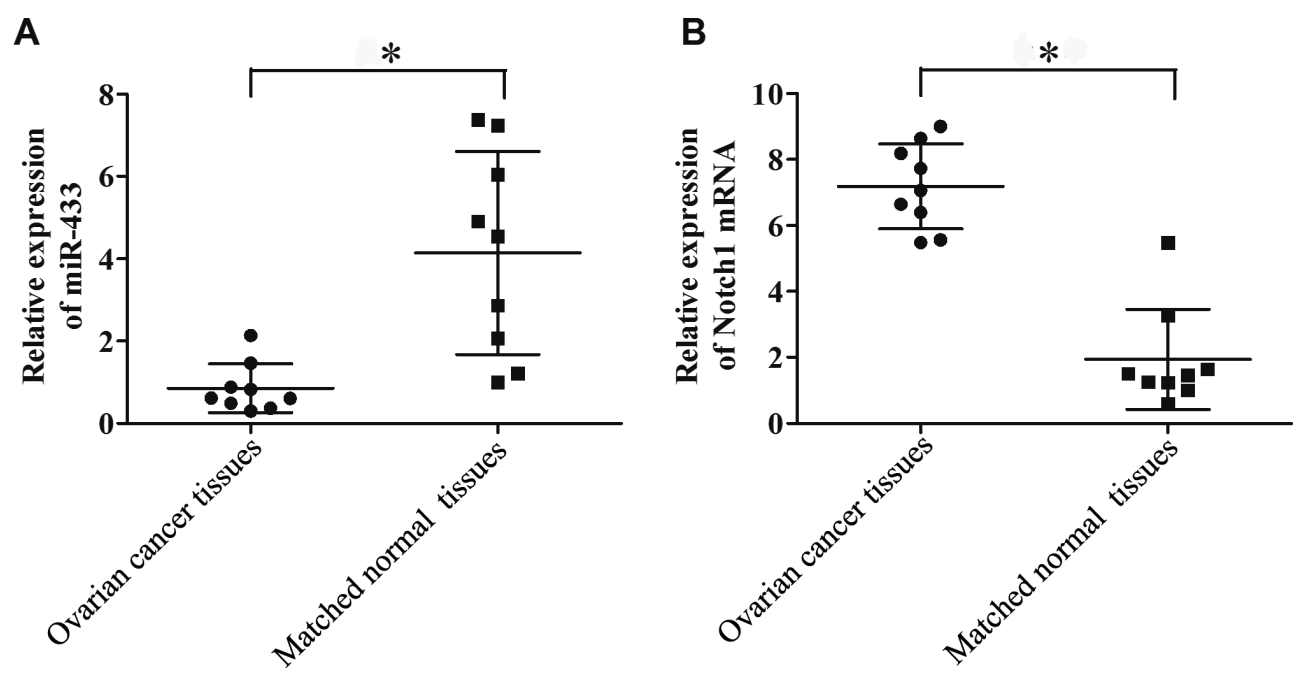

Figure 1. Analysis of the expression of miR-433 (A) and Notch1 mRNA (B) in ovarian cancer tissues and normal ovarian tissues by real-time PCR. ${ }^{*}$ indicated the significant differences compared with control group $(P<0.05)$.

respectively. Primer sequences using in our study were presented in Table 2.

Cell viability assay. Cells were harvested after $48 \mathrm{~h}$ of transfection and then seeded in 96-well plates. Cell proliferation was assessed using the Cell Counting Kit 8 (CCK-8, biosharp, China) for 5 consecutive days after seeding. In brief, $10 \mu \mathrm{l}$ of CCK-8 solution was added to each well and the plates were incubated at $37^{\circ} \mathrm{C}$ for $4 \mathrm{~h}$. Absorbance $(450 \mathrm{~nm})$ was measured using a microplate reader (Infinite ${ }^{ø}$ M1000 PRO, TECAN, Switzerland). All samples are performed in triplicate and following the manufacturer's instructions

Wound healing assay. The scratch wound healing assay is proved to be a sensitive method to determine cell migration capacity [25]. Cells were grown in culture dishes with serumfree RPMI-1640 medium for $24 \mathrm{~h}$ after transfection. When the cells reached $90 \%$ confluence and formed a confluent monolayer, a "scratch" of the cell monolayer was scraped in a straight line with a sterile pipette tip. Then cells continued to incubate for $24 \mathrm{~h}$. The scratch wounds were observed by phasecontrast microscope (Nikon, TS100, Japan) after 0 and $24 \mathrm{~h}$,

Table 2. Primer sequences used in our study

\begin{tabular}{ll}
\hline Primers & Sequence $\left(5^{\prime}-3^{\prime}\right.$ ) \\
\hline miR-433 RT & GTCGTATCCAGTGCAGGGTCCGAGGTATTCG- \\
& CACTGGATACGACACACCG \\
U6 RT & CGCTTCACGAATTTGCGTGTCAT \\
miR-433 Forward & GCGGCGGATCATGATGGGCTCC \\
miR-433 Reverse & CCAGTGCAGGGTCCGAGGT \\
U6 Forward & GCTTCGGCAGCACATATACTA \\
U6 Reverse & CGCTTCACGAATTTGCGTGTC \\
Notch1 Forward & ATGAGTTCCAGTGCGAGTGC \\
Notch1 Reverse & TAAGTGTTGGGTCCGTCCAG \\
\hline
\end{tabular}

respectively. Photographs were taken to access the ability of cell migration in each group. Each experiment was conducted in triplicate.

Transwell invasion assay. Cell invasion assay was carried out using BIOCOAT Matrigel Transwell chamber (BD, USA) with pore size of $8.0 \mu \mathrm{m}$. The inserts were placed into 24 -well plates containing $700 \mu \mathrm{l}$ of RPMI- 1640 medium for $30 \mathrm{~min}$ in a humidified incubator with $5 \% \mathrm{CO}_{2}$ at $37^{\circ} \mathrm{C}$ before seeding cells. After 48 hours' transfection, $5 \times 10^{4}$ cells in each group re-suspended in RPMI-1640 medium containing 5\% FBS were placed in each chamber. The lower compartment was loaded with full media containing $15 \% \mathrm{FBS}$ as the nutritional attractant. After incubated for $24 \mathrm{~h}$ at $37^{\circ} \mathrm{C}$, the chambers were fixed with $10 \%$ formaldehyde and stained with $1 \%$ Giemsa stain, and non-invaded cells were removed with a cotton swab. The translocated cells on the bottom of the chamber in 3 randomly selected fields were counted under a light microscope $(50 \times$ magnification).

Western blot analysis. Cells were harvested after transfected with miR-433 mimics for $72 \mathrm{~h}$. Cells were then washed with ice-cold PBS and lysed in RIPA lysis containing $0.01 \%$ protease and phosphatase inhibitor respectively. An equal amount of protein lysates were separated in $6 \%$ sodium dodecyl sulfate-polyacrylamide (SDS-PAGE) gel and electrophoretically transferred to a polyvinylidene fluoride membrane (Mllipore, USA). After being blocked with Western Blocking Reagent (10\%, Roche, Germany) for $2 \mathrm{~h}$, the membrane were incubated with anti-human rabbit polyclonal to Notch1 (1:750, Abcam, ab65297, USA) and mouse anti-human GAPDH (1:10000, Roche, Germany) overnight at $4^{\circ} \mathrm{C}$, followed by dylight-conjugated secondary antibody (Rockland, USA) at room temperature for 1 h. Finally, the blots were visualized and analyzed using the Odyssey IR imaging system (LI-COR Biosciences). 
SKOV3

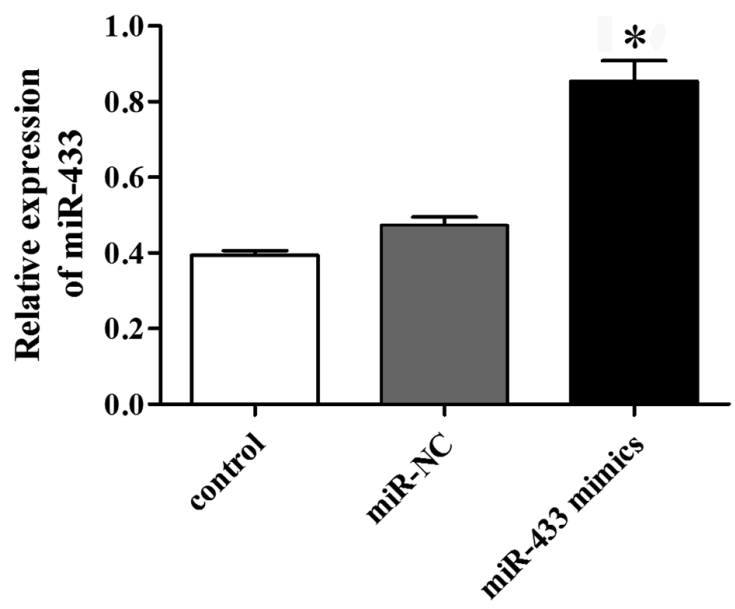

OVCAR3

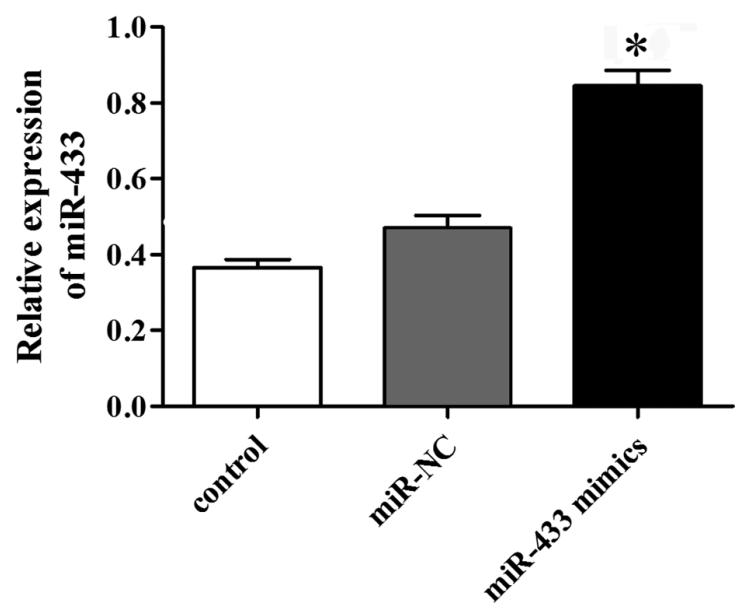

Figure 2. Real-time PCR showed MiR-433 was successfully over-expressed in both SKOV3 and OVCAR3 cells. ${ }^{*}$ indicated the significant differences compared with control group $(P<0.05)$.

Luciferace reporter assay. To confirm whether Notch1 was a target of miR-433, luciferace reporter assays were carried out using the Luciferase Reporter Assay System (Promega, USA). SKOV 3 and OVCAR3 cells was cultured in 24-well plates, and co-transfected with pGL3 vector (Promega, USA) containing miR-433 binding site of Notch1 3'UTR (WT) or deleting the sequence of binding site (MUT) with or without miR-433 mimics. After incubation for $48 \mathrm{~h}$, the luciferase activity was measured and normalized to the renilla luciferase activity.

Bioinformatics methods and statistical analysis. The miRNA targets were predicted by computer-aided algorithms based on the information of targetscan (http://www.targetscan.org/vert_61/) and miRanda (http://www.microrna.org/ microrna/home.do).

All data were presented as mean + standard deviation (SD) and subsequently analyzed by SPSS 17.0 statistical software. The statistical differences between groups were assessed by two-tailed Student's t-test or one-way ANOVA. A value of $P<$ 0.05 was considered statistically significant.

\section{Results}

Inverse expression of miR-433 and Notch 1 in ovarian cancer tissues. To investigate the expression of miR-433 and Notch1 mRNA in ovarian cancer tissues, real-time PCR was performed. The results showed that the expression of miR433 was markedly down-regulated in ovarian cancer tissues compared with normal ovarian tissues (Figure 1A, $P<0.05$ ). However, the expression of Notch1 mRNA in ovarian cancer tissues was significantly increased compared with normal ovarian tissues (Figure 1B, $P<0.05$ ).

MiR-433 was successfully over-expressed in SKOV3 and OVCAR3 cells. After transfected with miR-433 mimics, the expression of miR-433 in both SKOV3 and OVCAR3 cells was significantly up-regulated compared with normal control (Figure 2, $P<0.05$ ), while there were no significantly differences between miR-NC group and control group $(P>0.05)$, confirming that miR-433 was successfully over-expressed in ovarian cancer cells.

Overexpression of miR-433 inhibited cell migration and invasion of ovarian cancer cells. The effects of miR-433 in both SKOV3 and OVCAR3 cells were detected. The results of CCK-8 assay showed that proliferation of both SKOV3 and OVCAR3 cells that were transfected with miR-433 mimics was gradually inhibited compared normal control (Figure $3 \mathrm{~A}$ ), but there was no significant difference between them $(P>0.05)$. In addition, wound healing assay displayed the migration capacity of SKOV3 and OVCAR3 cells (Figure $3 \mathrm{~B}$ ). Similar results were obtained that the percentage of wound closure in miR-433 mimics transfected group was significantly lower than control group (Figure 3C, $P<0.05$ ). Besides, we detected the invasive ability of both SKOV3 and OVCAR3 cells using transwell invasion assay (Figure 3D). Similar results were obtained that the number of migration cells in miR-433 mimics transfected group was markedly decreased than control group (Figure $3 \mathrm{E}, P<0.05$ ). Taken together, miR-433 significantly inhibited the migration and invasion of ovarian cancer cells.

Notch1 was a direct target of miR-433. In this study, bioinformatic analysis methods were firstly used to predict that Notch1 was a potential target of miR-433 (Figure 4A). In order to further verify the predicted results, the expression of Notch1 protein in miR-433 mimics transfected cells was determined by western blot. The results showed that Notch1 protein expression in miR-433 mimics group was significantly inhibited compared with control group (Figure 4B, $P<0.05$ ). Moreover, we performed luciferase report assay to verify whether miR-433 could direct target the 3'UTR of Notch1 
A
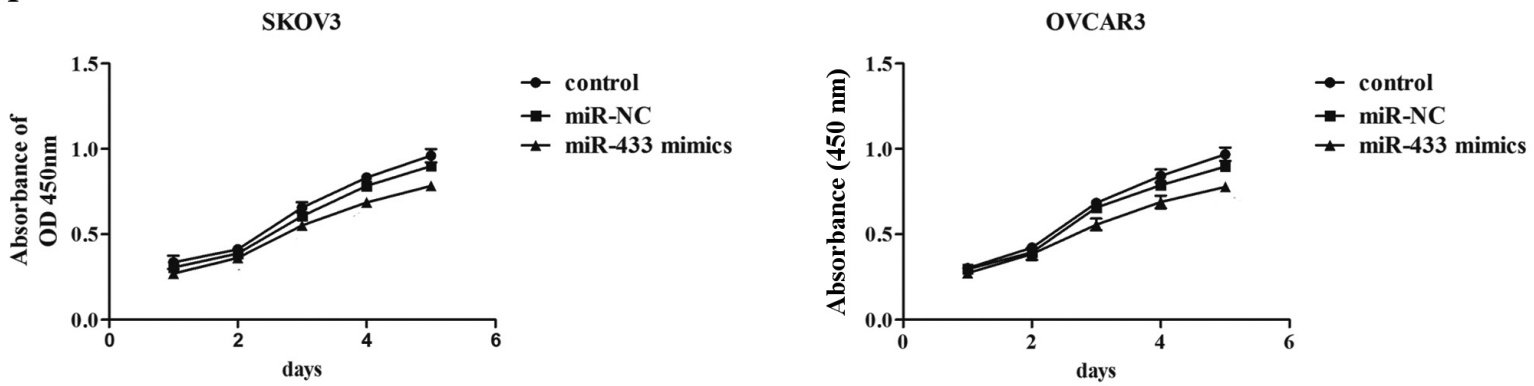

B
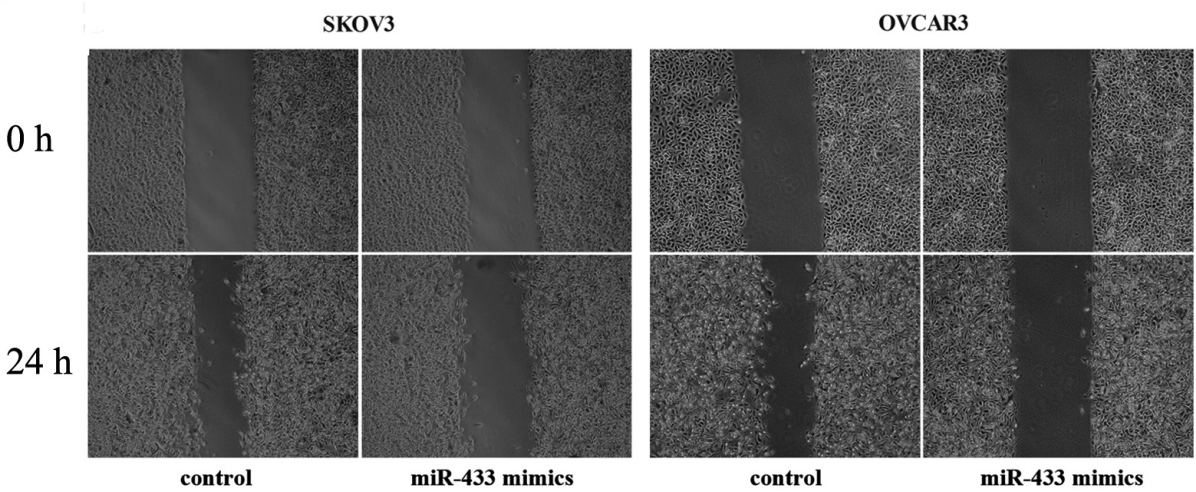

$\mathrm{C}$

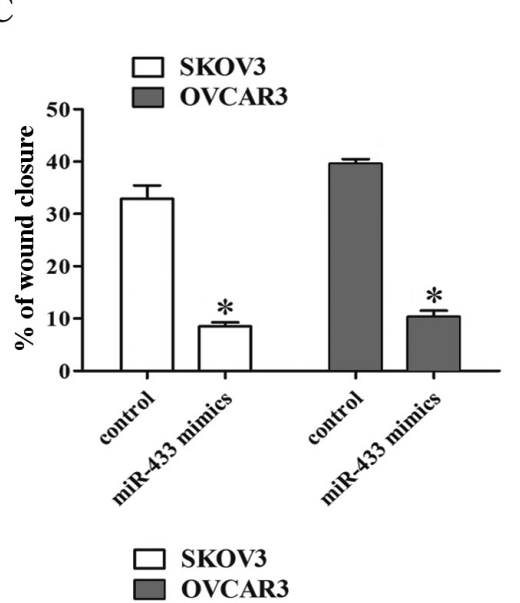

D

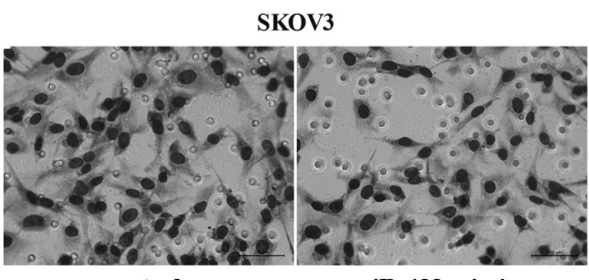

control

miR-433 mimics
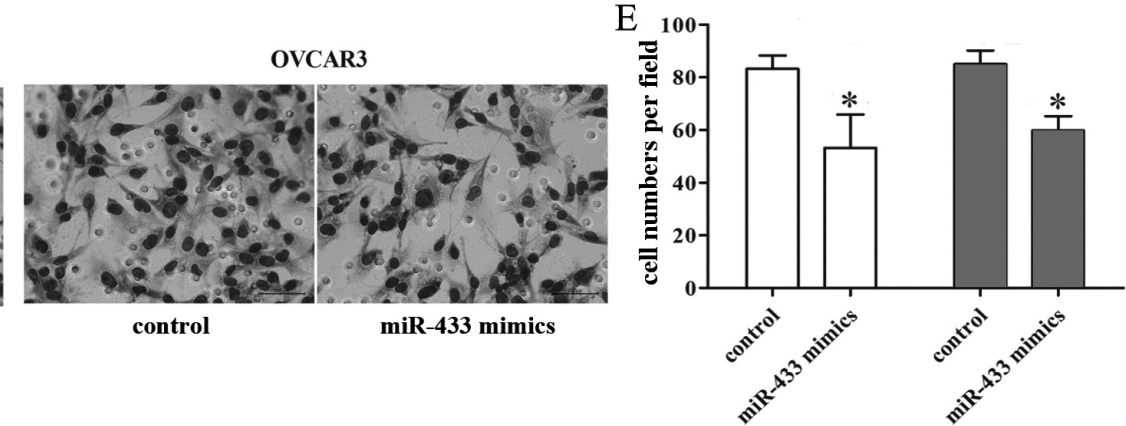

Figure 3. The effects of miR-433 on the proliferation, migration and invasion of ovarian cancer cells. A: CCK-8 assay showed the proliferation of SKOV3 and OVCAR3 in different groups in a experimental period of $5 \mathrm{~d}$. B: Wound healing assay displayed the percentage of wound closure in different groups at $\mathbf{~ h}$ and $\mathbf{2 4} \mathrm{h}$, indicating the migration capacity of SKOV3 and OVCAR3 cells in different groups. C: Quantification for the results of wound healing assay. D: Transwell invasion assay showed the invasive number of cells in different groups after $24 \mathrm{~h}$ of treatment. E: Quantification for the results of Transwell invasion assay. ${ }^{*}$ indicated the significant differences compared with normal control group $(P<0.05)$.

mRNA. Expected results was obtained that co-expression of miR-433 markedly suppressed the luciferase report activity of the wild-type Notch1 3'UTR but not the mutant Notch1 3'UTR (Figure 4C, $P<0.05$ ). To sum up, Notch1 was a direct target of miR-433.

Down-regulation of Notch1 inhibited the invasion of ovarian cancer cells. Western blot analysis showed that the expression of Notch1 protein in SKOV3 cells was successfully knocked down by Notch 1 siRNA (Figure 5A, $P<0.05$ ). In addition, we found that down-regulation of Notch 1 expression could gradually inhibit proliferation of SKOV3 cells (Figure $5 \mathrm{~B})$, but there was no significant difference in cell proliferation between Notch1 siRNA group and control group $(P>0.05)$. Besides, transwell invasion assay displayed that the invasive SKOV 3 cells in Notch1 siRNA group and control group (Figure 5C), and the results showed that down-regulation of Notch1 expression could markedly decreased the number of invasive cells (Figure 5D, $P<0.05$ ). 
A

\author{
Position 713-720 of Notch1 3'UTR \\ hsa-miR-433
}

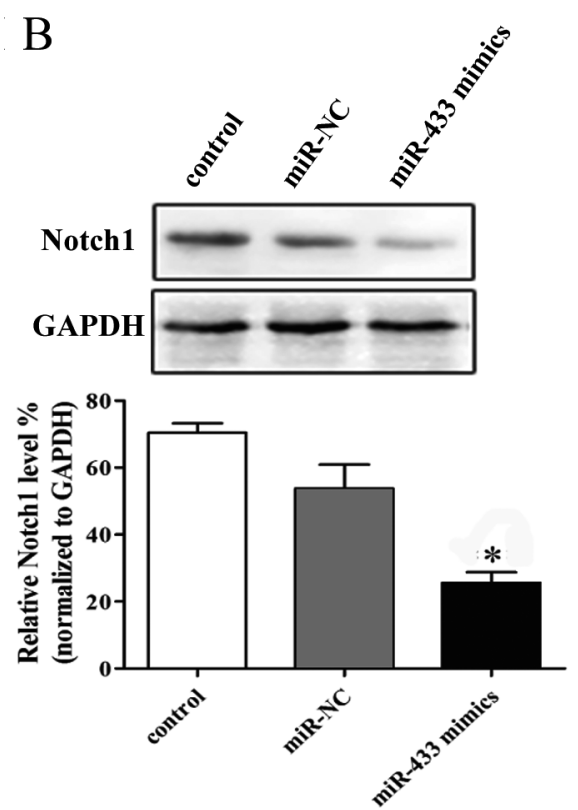

\section{1 ...GCACCCAUGGUACOAAUCAUGAA... \\ 3' UGUGGCUCCUCGG GUAGUACUA}

C

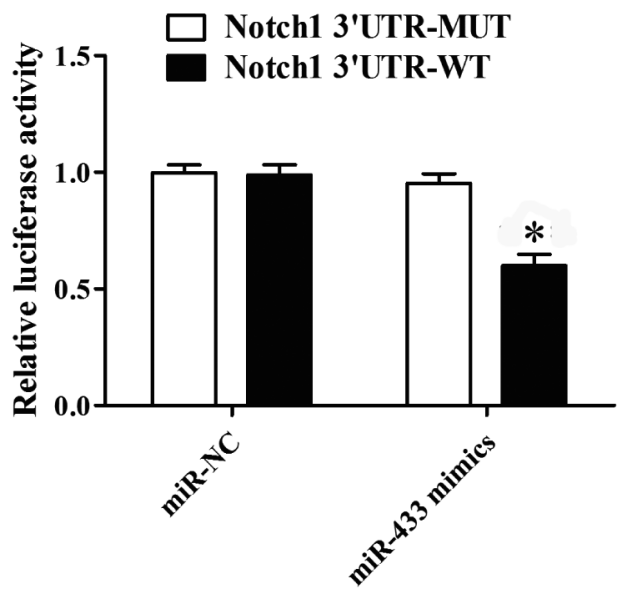

Figure 4. Notch1 was a directly target of miR-433. A: The results of bioinformatic analysis methods. B: The expression of Notch1 protein expression in different groups. C: Luciferase report assay showed miR-433 could directly target the 3'UTR of Notch1 mRNA. * indicated the significant differences compared with normal control group $(P<0.05)$.

\section{Discussion}

Ovarian cancer is a serious and under-recognized threat to women's health due to its high incidence and mortality. Accumulating evidence has shown that miRNAs play an important role in the development of various cancers. In the present study, we found that miR-433 was down-regulated in ovarian cancer tissues, and overexpression of miR-433 could significantly inhibit cell migration and invasion of ovarian cancer cells. Moreover, miR- 433 could target Notch1 directly, and down-regulation of Notch1 markedly inhibited the invasion of ovarian cancer cells.

Accumulating evidence has shown that miRNAs are critical regulators in cancer-related processes and may be novel diagnostic and therapeutic targets for tumor treatment [26]. In this study, we identified that miR-433 was down-regulated in ovarian cancer tissues. Moreover, miR- 433 mimics were transfected into ovarian cancer cells and confirmed that over-expression of miR-433 may exert an inhibitory effect on cell migration and invasion of ovarian cancer cells. Consistently, miR-433 is shown to act as tumor suppressors in gastric cancer and may serve as a diagnostic and therapeutic biomarker for human GC treatment in the future $[27,28]$. Also, miR-433 is reported to negatively regulate the proliferation and erythropoiesis of hematopoietic cells, thus to play a tumor suppressor role in myeloproliferative neoplasms [29]. Therefore, our results imply that miRNA-433 may function as a tumor suppressor in the development of ovarian cancer. However, a recent study affirms that over-expression of miR-433 in ovarian cancer cells can promote resistance to paclitaxel through induce cellular senescence [20]. Thus, the key roles of miR-433 in regulating the malignant behaviors of ovarian cancer cells are still needed to further explored.

Furthermore, Notch 1 was confirmed as a directly target of miR-433 in our study. The Notch signaling cascade is an evolutionarily conversed mechanism which plays a crucial role in controlling proliferation, differentiation, and apoptosis events [30]. Aberrant activation of Notch signaling has been reported to be implicated in tumorigenesis [31]. Notch1 is a core component of Notch signaling in mammals [32]. Notch1 functions as a key player in ovarian cancer $[33,34]$ and breast cancer [35]. In addition, down-regulation of Notch1 is also reported to lead to inhibit cell invasion in pancreatic cancer cells [36]. Furthermore, microRNA-34a can play inhibitory roles in cell migration and invasion in invasive urothelial bladder carcinoma by targeting Notch1 [37]. In our study, 
A
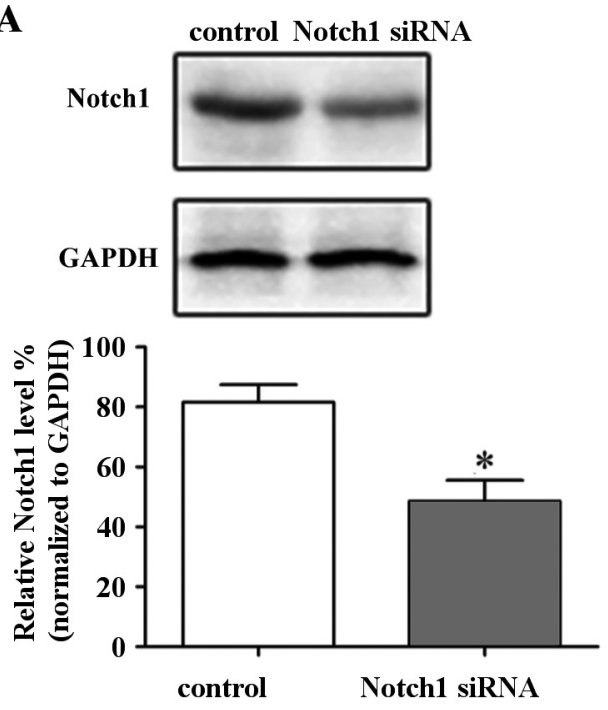

C

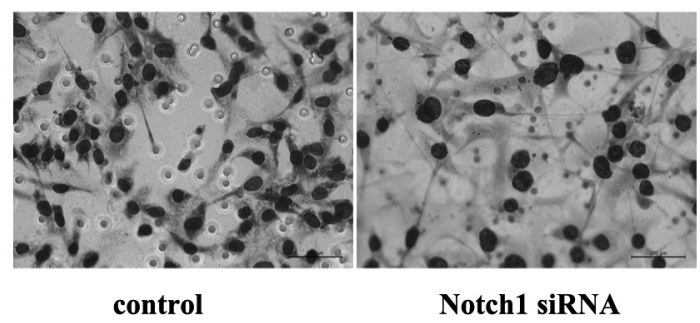

B
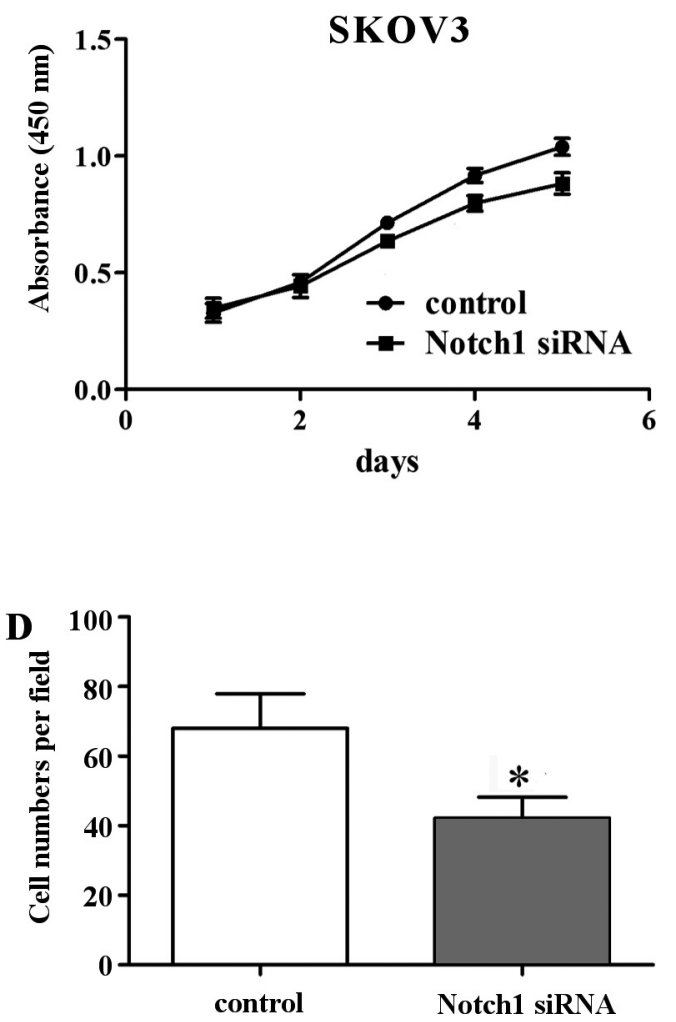

Figure 5. The effects of Notch1 on the proliferation, migration and invasion of ovarian cancer cells. A: Western blot analysis showed that the expression of Notch1 protein in SKOV3 cells. B: CCK-8 assay showed the proliferation of SKOV3 in different groups. C: Transwell invasion assay displayed that the invasive SKOV3 cells in Notch1 siRNA group and control group. D: The invasive number of cells in different groups obtained by Transwell invasion assay. ${ }^{*}$ indicated the significant differences compared with normal control group $(P<0.05)$.

down-regulation of Notch1 inhibited the invasion of ovarian cancer cells. Thus, our results are in line with previous findings and suggest that Notch1 may contribute to the cell proliferation and invasion in the development of ovarian cancer. Besides, targeting Notch signaling pathway is an effective strategy to overcome drug resistance for cancer therapy [38]. McAuliffe et al. also demonstrated that targeting Notch pathway sensitized ovarian tumors to platinum therapy [39]. It can therefore be speculated that targeting Notch1 may have feasibility and application prospects in cancer therapy. Taken together, miR433 may inhibit malignant progression of ovarian cancer via targetingNotch1.

Besides, a previous study has confirmed that the cAMP response element-binding protein CREB1 is the first identified target of miR-433 in liver cancer and $\mathrm{miR}-433$ can repress cell migration in hepatocellular carcinoma (HCC) via regulating CREB1 [40]. Also, miR-433 can increase the sensitivity to 5-fluorouracil in HeLa cells via negatively regulating TYMS [19]. These findings suggest that there are other targets of miR-433 besides Notch1. Therefore, whether miR-433 plays a key role in ovarian cancer development via regulating other targets is still further investigated. In addition, because miR433 was markedly down-regulated in ovarian cancer tissues compared with normal ovarian tissues in our study, we only performed overexpression experiment to observe the effect of miR-433 on the malignant behaviors in ovarian cancer. If miR-433 knockdown experiment was performed, the function of miR-433 will be clear demonstrated. In combination, more experimental validations are valuable need to verify our observation.

\section{Conclusion}

In conclusion, our findings indicate that miR-433 may inhibit cell migration and invasion in the development of ovarian cancer via down-regulation of Notch1. Notch1 may serve as a potential target in cancer therapy. Our findings provide a new insight into the progression of ovarian cancer and may have potential value for the diagnosis and treatment of this disease. 


\section{References}

[1] JAYSON GC, KOHN EC, KITCHENER HC, LEDERMANN JA. Ovarian cancer. The Lancet 2014; 384: 1376-1388. http:// dx.doi.org/10.1016/S0140-6736(13)62146-7

[2] SIEGEL RL, MILLER KD, JEMAL A. Cancer statistics, 2015. CA Cancer J Clin 2015; 65: 5-29. http://dx.doi.org/10.3322/ caac. 21254

[3] BEREK JS, CRUM C, FRIEDLANDER M. Cancer of the ovary, fallopian tube, and peritoneum. Int J Gynecol Obstet 2012; 119: S118-S129. http://dx.doi.org/10.1016/S0020-7292(12)60025-3

[4] WANG K, LI Y, JIANG Y-Z, DAI C-F, PATANKAR MS et al. An endogenous aryl hydrocarbon receptor ligand inhibits proliferation and migration of human ovarian cancer cells. Cancer Lett 2013; 340: 63-71. http://dx.doi.org/10.1016/j. canlet.2013.06.026

[5] LI Y, WANG K, JIANG Y-Z, CHANG X-W, DAI C-F et al. 2, 3, 7, 8-Tetrachlorodibenzo-p-dioxin (TCDD) inhibits human ovarian cancer cell proliferation. Cell Oncol 2014; 37: 429-437. http://dx.doi.org/10.1007/s13402-014-0206-4

[6] GUO Y, TIAN P, YANG C, LIANG Z, LI M et al. Silencing the double-stranded RNA binding protein DGCR8 inhibits ovarian cancer cell proliferation, migration, and invasion. Pharm Res 2015; 32: 769-778. http://dx.doi.org/10.1007/ s11095-013-1219-9

[7] WANG Z, LI Y, BANERJEE S, SARKAR FH. Emerging role of Notch in stem cells and cancer. Cancer Lett 2009; 279: 8-12. http://dx.doi.org/10.1016/j.canlet.2008.09.030

[8] YUN L, HE X, QIU H, QI C, WANG F et al. Suppression of the epithelial-mesenchymal transition by SHARP1 is linked to the NOTCH1 signaling pathway in metastasis of endometrial cancer. BMC cancer 2014; 14: 1-10.

[9] PRADIP N, KUMARAVEL S, SUDHIR K. Activated Notch1 inhibits p53-induced apoptosis and sustains transformation by human papillomavirus type $16 \mathrm{E} 6$ and E7 oncogenes through a PI3K-PKB/Akt-dependent pathway. J Virol 2003; 77: 7106-7112. http://dx.doi.org/10.1128/JVI.77.12.7106$\underline{7112.2003}$

[10] ROSE SL, KUNNIMALAIYAAN MJ, SEILER N. Notch 1 signaling is active in ovarian cancer. Gynecol Oncol 2010; 117: 130-133. http://dx.doi.org/10.1016/j.ygyno.2009.12.003

[11] BARTEL DP . MicroRNAs genomics, biogenesis, mechanism, and function. Cell 2004; 116: 281-297. http://dx.doi. org/10.1016/S0092-8674(04)00045-5

[12] ESTELLER M. Non-coding RNAs in human disease. Nat Rev Genet 2011; 12: 861-874. http://dx.doi.org/10.1038/nrg3074

[13] NICOLOSO MS, R. SHIMIZU, M. ROSSI, S. CALIN, GA. MicroRNAs--the micro steering wheel of tumour metastases. Nat Rev Cancer 2009; 9: 293-302. http://dx.doi.org/10.1038/ $\underline{\operatorname{nrc} 2619}$

[14] IORIO MV, VISONE R, DI LEVA G, DONATI V, PETROCCA F et al. MicroRNA signatures in human ovarian cancer. Cancer Res 2007; 67: 8699-8707. http://dx.doi.org/10.1158/0008-5472. CAN-07-1936

[15] NAM EJ, YOON H, KIM SW, KIM H, KIM YT et al. MicroRNA expression profiles in serous ovarian carcinoma. Clin Cancer
Res 2008; 14: 2690-2695. http://dx.doi.org/10.1158/1078-0432. CCR-07-1731

[16] CHENG W, LIU T, WAN X, GAO Y, WANG H. MicroRNA199a targets CD44 to suppress the tumorigenicity and multidrug resistance of ovarian cancer-initiating cells. FEBS J 2012; 279: 2047-2059. http://dx.doi.org/10.1111/j.1742-4658 2012.08589.x

[17] WANG XC, MA Y, MENG PS, HAN JL, YU HY et al. miR-433 inhibits oral squamous cell carcinoma (OSCC) cell growth and metastasis by targeting HDAC6. Oral Oncol 2015; 51: 674682. http://dx.doi.org/10.1016/j.oraloncology.2015.04.010

[18] YANG Z, TSUCHIYA H, ZHANG Y, HARTNETT ME, WANG L. MicroRNA-433 inhibits liver cancer cell migration by repressing the protein expression and function of cAMP response element-binding protein. J Biol Chem 2013; 288: 28893-28899. http://dx.doi.org/10.1074/jbc.M113.502682

[19] GOTANDA K, HIROTA T, MATSUMOTO N, IEIRI I. MicroRNA-433 negatively regulates the expression of thymidylate synthase (TYMS) responsible for 5-fluorouracil sensitivity in HeLa cells. BMC Cancer 2013; 13: 369. http:// dx.doi.org/10.1186/1471-2407-13-369

[20] WEINER-GORZEL K, DEMPSEY E, MILEWSKA M, MCGOLDRICK A, TOH V et al. Overexpression of the microRNA miR-433 promotes resistance to paclitaxel through the induction of cellular senescence in ovarian cancer cells. Cancer Med 2015; 4: 745-758. http://dx.doi.org/10.1002/ cam4.409

[21] FURLONG F, FITZPATRICK P, O'TOOLE S, PHELAN S, MCGROGAN B et al. Low MAD2 expression levels associate with reduced progression-free survival in patients with high-grade serous epithelial ovarian cancer. J Pathol 2012; 226: 746-755. http://dx.doi.org/10.1002/path.3035

[22] STOYANOVA T, FALTERMEIER C, SMITH B, GOLDSTEIN A, ZHANG $\mathrm{X}$ et al. Notch1 as a key mediator in promoting advanced castration-resistant prostate cancer. Cancer Res 2015; 75: 4985-4985. http://dx.doi.org/10.1158/1538-7445. $\underline{\mathrm{AM} 2015-4985}$

[23] NGUYEN D, RUBINSTEIN L, SHERMAN ME, TOMASZEWSKI JE, TAKEBE $N$ et al. Differential expression of Notch1 in lung, ovarian and breast cancers. Cancer Res 2014; 74: 3838-3838. http://dx.doi.org/10.1158/1538-7445.AM2014$\underline{3838}$

[24] LIVAK KJ ST. Analysis of Relative Gene Expression Data Using Real-Time Quantitative PCR and the 2(-Delta Delta C(T))Method. METHODS 2001; 25: 402-408. http://dx.doi. org/10.1006/meth.2001.1262

[25] CORY G. Scratch-wound assay. In: editors. Cell Migration. Springer; 2011. p. 25-30. http://dx.doi.org/10.1007/978-1$\underline{61779-207-6 \quad 2}$

[26] KASINSKI AL, SLACK FJ. MicroRNAs en route to the clinic: progress in validating and targeting microRNAs for cancer therapy. Nat Rev Cancer 2011; 11: 849-864. http://dx.doi. org/10.1038/nrc3166

[27] GUO L-H, LI H, WANG F, YU J, HE J-S. The tumor suppressor roles of miR-433 and miR-127 in gastric cancer. Int J Mol Sci 2013; 14: 14171-14184. http://dx.doi.org/10.3390/ ijms140714171 
[28] YANG O, HUANG J, LIN S. Regulatory effects of miRNA on gastric cancer cells. Oncol Lett 2014; 8: 651-656. http://dx.doi. org/10.3892/ol.2014.2232

[29] LIN X, RICE K, BUZZAI M, HEXNER E, COSTA F et al. miR433 is aberrantly expressed in myeloproliferative neoplasms and suppresses hematopoietic cell growth and differentiation. Leukemia 2013; 27: 344-352. http://dx.doi.org/10.1038/ leu.2012.224

[30] ARTAVANIS-TSAKONAS S, RAND MD, LAKE RJ. Notch signaling cell fate control and signal integration in development. Science 1999; 284: 770-776. http://dx.doi.org/10.1126/ science.284.5415.770

[31] LEONG KG, KARSAN A. Recent insights into the role of Notch signaling in tumorigenesis. Blood 2006; 107: $2223-$ 2233. http://dx.doi.org/10.1182/blood-2005-08-3329

[32] LAI EC. Notch signaling control of cell communication and cell fate. Development 2004; 131: 965-973. http://dx.doi. org/10.1242/dev.01074

[33] WANG M, WANG J, WANG L, WU L, XIN X. Notch1 expression correlates with tumor differentiation status in ovarian carcinoma. Med Oncol 2010; 27: 1329-1335. http://dx.doi. org/10.1007/s12032-009-9384-8

[34] ROSE SL, KUNNIMALAIYAAN M, DRENZEK J, SEILER $\mathrm{N}$. Notch 1 signaling is active in ovarian cancer. Gynecol Oncol 2010; 117: 130-133. http://dx.doi.org/10.1016/j. ygyno.2009.12.003

[35] ZHANG X, ZHAO X, SHAO S, ZUO X, NING Q et al. Notch1 induces epithelial-mesenchymal transition and the cancer stem cell phenotype in breast cancer cells and STAT3 plays a key role. Int J Oncol 2015; 46: 1141-1148.

[36] WANG Z, BANERJEE S, LI Y, RAHMAN KW, ZHANG $\mathrm{Y}$ et al. Down-regulation of Notch-1 inhibits invasion by inactivation of nuclear factor- $\kappa \mathrm{B}$, vascular endothelial growth factor, and matrix metalloproteinase- 9 in pancreatic cancer cells. Cancer Res 2006; 66: 2778-2784. http://dx.doi. org/10.1158/0008-5472.CAN-05-4281

[37] ZHANG C, YAO Z, ZHU M, MA X, SHI T et al. Inhibitory effects of microRNA-34a on cell migration and invasion of invasive urothelial bladder carcinoma by targeting Notch1. Journal of Huazhong University of Science and Technology [Medical Sciences] 2012; 32: 375-382. http://dx.doi. org/10.1007/s11596-012-0065-Z

[38] WANG Z, LI Y, AHMAD A, AZMI AS, BANERJEE S et al. Targeting Notch signaling pathway to overcome drug resistance for cancer therapy. Biochim Biophys Acta 2010; 1806: 258-267. http://dx.doi.org/10.1016/j.bbcan.2010.06.001

[39] MCAULIFFE SM, MORGAN SL, WYANT GA, TRAN LT, MUTO KW et al. Targeting Notch, a key pathway for ovarian cancer stem cells, sensitizes tumors to platinum therapy. PNAS 2012; 109: E2939-E2948. http://dx.doi.org/10.1073/ pnas. 1206400109

[40] YANG Z, TSUCHIYA H, ZHANG Y, HARTNETT ME, WANG L. MicroRNA-433 inhibits liver cancer cell migration by repressing the protein expression and function of cAMP response element-binding protein. J Biol Chem 2013; 288: 28893-28899. http://dx.doi.org/10.1074/jbc.M113.502682 